\title{
ENSURING THE QUALITY OF TREATMENT OF HOLES IN PRODUCTS FROM POLYMERIC COMPOSITE MATERIALS
}

\author{
V.M. Yaroslavtsev \\ mt13@bmstu.ru
}

Bauman Moscow State Technical University, Moscow, Russian Federation

\begin{tabular}{|c|c|}
\hline Abstract & Keywords \\
\hline $\begin{array}{l}\text { The generalized results of industrial and laboratory } \\
\text { tests of unconventional technologies for improving } \\
\text { the quality of manufacturing holes in products } \\
\text { made of fibrous polymeric and layered hybrid } \\
\text { composite materials are considered. Developed in } \\
\text { BMSTU combined methods of processing, non- } \\
\text { standard cutting tools and devices that ensure the } \\
\text { combination of diverse energy impact on the } \\
\text { treated surface, as well as the targeted creation of } \\
\text { the required energy state of the material were given. } \\
\text { It is shown that the application of the cutting } \\
\text { method with additional technological coating on } \\
\text { the operations of reaming, deployment and boring } \\
\text { provides, depending on the processing conditions, a } \\
\text { decrease in surface roughness of } 1-3 \text { classes (from } 4 \\
\text { to } 5-7 \text { classes). Drilling with a thermo-mechanical } \\
\text { impact on the cutting layer reduces the roughness } \\
\text { parameter from } R z=40-20 \mu \text { m (class } 4 \text { ) to Ra }= \\
=2.5-1.6 \mu \text { m (class } 6 \text { ). At the same time on the } \\
\text { treated surfaces, fluffiness is completely eliminated. } \\
\text { The possibility of increasing the productivity and } \\
\text { quality of processing holes in multilayer hybrid } \\
\text { composite materials by the use of special-purpose } \\
\text { drills, which clean the processed surface on the } \\
\text { backward pass of the tool, is considered. Practical } \\
\text { recommendations are given to ensure defect-free } \\
\text { processing of the hole edges at the tool inlet and } \\
\text { outlet using additional coatings, as well as the } \\
\text { creation of compressive stresses in the treatment } \\
\text { area with the help of special tools }\end{array}$ & $\begin{array}{l}\text { Polymer composite materials, } \\
\text { hole processing, hole edges, quality } \\
\text { of processing, cutting with addi- } \\
\text { tional technological coating, } \\
\text { cutting with thermo-mechanical } \\
\text { impact, drill with additional } \\
\text { cutting edges }\end{array}$ \\
\hline
\end{tabular}

Introduction. The production of holes in products made of polymer composites is associated with the formation of a number of characteristic defects, such as large numerical values of surface roughness parameters, destruction of the surface layer, chipping of the edges of the hole, separation of the material at the 
tool entrance to the hole and outlet from it and others [1-6], which causes significant difficulties in ensuring the quality of products.

The greatest difficulties in obtaining holes of the required quality arise when processing poly-reinforced hybrid composite materials containing heterofiber filaments, significantly differing in strength and elastic properties, as well as spatial multicomponent structures of composite materials and, especially, organoplastics or compositions containing organofibers. Cutting such compositions as a result of cutting the filler fibers leads to the formation of a pile on the treated surface $[3,4,7,8]$, and the free surface areas of the pile are characterized by significant roughness, the presence of pores, cavities, local chips and detachments of the matrix.

Formulation of the problem. Ensuring high quality and competitiveness of manufactured products from composite materials, taking into account the specifics of their physical and mechanical properties and patterns of the cutting process, necessitated the creation and application of innovative processing methods, characteristic in some cases only for cutting conditions of polymer composite materials. The task of improving the machinability cutting of composite materials, in particular in the manufacture of holes, in BMSTU decided through the development of technologies that can be attributed to such areas of improvement of the cutting process, such as the development of new processing methods, new tooling designs, the use of combined energy impacts, etc.

Solution methods and results. One of the impactive means of improving the manufacturing process of holes in polymer composite materials is the cutting method with additional technological coating $[4,8]$, which helps remove pile and reduce the roughness of the treated surface.

The method consists of applying a temporary technological coating, which can be used in various types of binder used in the manufacture of polymer composites, or adhesives and varnishes having chemical affinity with the base material on the treated surface obtained by passing the cutting tool to the final size. The coating fills the irregularities of the micro and macro relief, tying up the pile after curing and forming a strong adhesive joint with it. The cured coating is removed with a cutting tool when re-passing into the final size, and the pile, firmly held by the binder, is also cut off. In this case, as shown by cutting studies with additional technological coating when turning the outer surfaces $[4,8]$, the roughness of the machined surface is significantly reduced, defects in the surface layer of the product due to the chip formation process on the previous tool pass are partially eliminated. 
V.M. Yaroslavtsev

Similar results were obtained when studying the technological capabilities of the cutting method with additional technological coating on various hole processing operations with an axial tool.

Experiments on drilling holes in polymer composites with their subsequent reaming after applying a layer of additional technological coating were carried out on ring samples of "Viscose-77" organoplastic of spiral winding. Processed through holes with a depth of $15 \mathrm{~mm}$. Studies were carried out on a vertical drilling machine model $2 \mathrm{H} 118$ using twist drills with diameters of $8.9 ; 9$ and $9.1 \mathrm{~mm}$ from high-speed steel P9K5, having the following sharpening geometry of the cutting part: $2 \varphi=90^{\circ} ; \alpha=15^{\circ}$.

The processing of holes in organoplastic material is characterized by shrinkage of the diametrical size of the holes being produced. Therefore, one of the objectives of the study is to assess changes in the quality indicators of the treated surfaces during drilling with the use of an additional technological coating, depending on the conditions for removing the cured coating, determining the optimal position of the final reaming surface with respect to the joint of the previously machined drilling surface and the layer of the temporary technological coating.

The experiments were performed in the following sequence: initially, the holes were drilled using a drill with a diameter of $9.1 \mathrm{~mm}$. At the same time, in some areas of the treated surfaces, as well as at the tool inlet and outlet, the pile was raised to a height of $2 \mathrm{~mm}$ and there was no pronounced hole edge. The hole shrinkage in diameter was about $0.1 \mathrm{~mm}$. The roughness of the pile-free surface areas corresponded to $R z=25-32 \mu \mu \mathrm{m}$. A coating of $1.5-2 \mathrm{~mm}$ of epoxy resin class EDT-10 with a hardener of 10:1 was applied to the treated surface of the hole. After polymerization of the binder, reaming was carried out using drills of various diameters: $8.9 ; 9 ; 9.1 \mathrm{~mm}$. To measure the height of the roughness, the holes were opened.

It has been established that the smallest surface roughness value $(R z=$ $=12.7 \mu \mathrm{m}$ ) is achieved when reaming holes, when the applied process coating is completely removed and the cutting line passes directly through the joint. This corresponds to the condition of coincidence of the diameter of the drill used for reaming, with the diameter of the hole after the previous drilling, taking into account its shrinkage. In our case - a drill with a diameter of 9 $\mathrm{mm}$ was used. This completely eliminates surface fluffiness.

Drilling holes with $8.9 \mathrm{~mm}$ diameter drill bits does not ensure complete removal of the additional technological coating; individual chips in the polymerized binder are observed on the surface, which generally manifests itself in an increase in the roughness parameter $R z$ to $20 \mu \mathrm{m}$. When drilling 
holes with additional technological coating drills with a diameter of $9.1 \mathrm{~mm}$, the coating is completely removed; moreover, this results in the cutting of new fibers of the blank material. As a result, the resulting quality of the machined surface differs little from the quality of the surface layer after conventional drilling.

The surface roughness of the hole after drilling can be significantly reduced by subsequent deployment with additional technological coating. Experiments have shown that the deployment of holes with a diameter of $9 \mathrm{~mm}$ using a technological coating reduces the numerical value of the roughness parameter $R z=28 \mu \mathrm{m}$ obtained after drilling to $R z=4 \mu \mathrm{m}$. It should be noted that the deployment without the use of coating somewhat worsens the surface roughness of the hole, obtained after drilling, due to the additional cutting of new fibers and increase in size an existing pile.

The use of additional technological coating contributes to a significant improvement in the quality of the treated surfaces and boring holes in products made of polymer composite materials. For research, we used ring samples from organoplastic "Viscose-77" with a hole diameter of $110 \mathrm{~mm}$ and initial surface roughness after preliminary boring under the application of a layer of additional technological coating $R z=20-25 \mu \mathrm{m}$ (class 4). Boring with a coating was carried out on a machine $16 \mathrm{~K} 20$ turning screw cutter.

In Fig. 1 shows the curve of change of the surface roughness parameter $R a$ depending on the position of the processed surface during the finishing, final tool passage relative to the reference surface (" 0 " on the $\mathrm{x}$-axis), which is a joint of two materials: the original blank ("Viscose-77") and an additional layer technological coating (EDT-10).

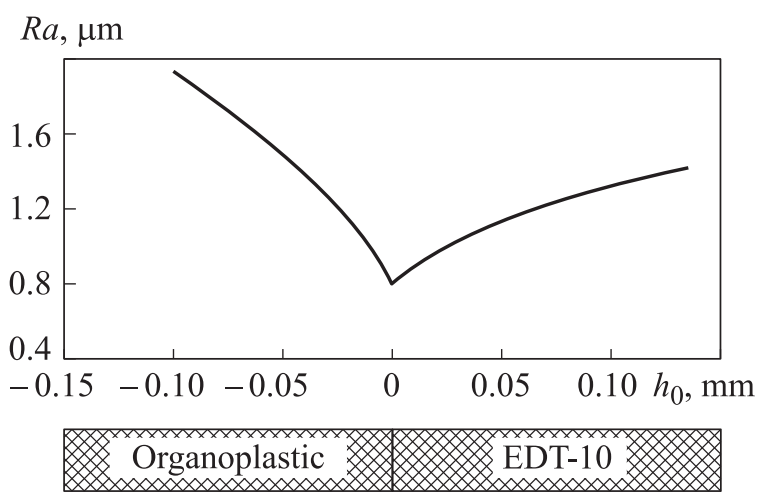

Fig. 1. Dependence of surface roughness $R a$ on the position of the processed surface $h_{0}$ relative to the joint $\left(h_{0}=0\right)$ of the blank material and additional technological coating during boring. Cutter P6M5:

$\gamma=30^{\circ} ; \alpha=20^{\circ} ; \alpha_{1}=10^{\circ} ; \varphi=45^{\circ} ; \varphi_{1}=1^{\circ} ; r_{\mathrm{B}}=2.5 \mathrm{~mm} ; v=2.5 \mathrm{~m} / \mathrm{s} ; S=0.11 \mathrm{~mm} / \mathrm{rev}$ 
V.M. Yaroslavtsev

From the Fig. 1 it follows that the smallest roughness value $R a=0.8 \mu \mathrm{m}$ (class 7), like drilling and deployment with additional technological coating, is achieved at zero thickness of the coating layer after final processing. Incomplete removal of additional technological coating $\left(h_{0}>0\right)$ or penetration of the tool into the main material of the blank $\left(h_{0}<0\right)$ on the final pass causes a significant increase in surface roughness (Fig. 1).

One of the technological ways to solve the problem of improving the quality of processing holes in products made of polymer composite materials is the use of an additional thermo-mechanical impact on the treated surface [9, 10]. The combined energy impact (thermal and mechanical) changes the state and properties of the material of the surface layer after cutting processing, which contributes to improving the quality of the holes being made: reducing the surface roughness and eliminating the pile. The technological parameters of such a thermo-mechanical impact are determined by the nature of the binder. So, when using EDT-10 epoxy resin as a binder, the most rational temperatures of short-term thermal exposure are $T=200-300{ }^{\circ} \mathrm{C}$, at which only the binder softens without a noticeable change in its structure as a result of thermal destruction. The pressure of a special mechanical device on a viscous surface layer of a polymer composite material ensures a strong connection between the pile formed during the previous treatment and the binder, and forms the surface of the product. The rotational and (or) translational movement of such a device contributes to the uniform distribution of the softened (pseudo-liquid) binder over the entire treated surface, pressing into the binder of the protruding pile. The dynamic process of restructuring the structure of the material (formation of the "third body" [11]) is developing in the area of the moving contact.

It has been experimentally shown [9] that the use of a thermo-mechanical impact during the turning process of products from organoplastic CBM-6 allows you to completely eliminate fluffiness and reduce the surface roughness parameter from $R z=32-16 \mu \mathrm{m}$ ( $4-5$ classes) to $R a=2.5-1.25 \mu \mathrm{m}$ (6th class).

A rational means of practical implementation of the thermo-mechanical impact on the machined surface when drilling holes is a technological method based on the use of friction forces [9]. In this case, for processing the holes, use drills with an elongated attachment (fixing-based) part of the tool. In the experiments, spiral drills from high-speed steel R6M5 with a cylindrical shank with diameters of $11 \mathrm{~mm}$ (2300-2832 GOST 4010-77), $14.50 \mathrm{~mm}$ (2300-2859 GOST 4010-77) and $18 \mathrm{~mm}$ (2300-2875 GOST 4010-77) were used. When processing through holes in blanks made of organoplastic CBM-6, the tool was 
moved in the axial direction (inning movement $S$ ) for the full length of its working part, as well as for the length of the shank, free from fastening in the drill chuck (Fig. 2). As a result, a cylindrical tail part of the tool enters the resulting hole, which has a shrinkage of the diameter after drilling, with a tension $(\sim 0.1 \mathrm{~mm}$ to a diameter of $10 \mathrm{~mm}$ ) (Fig. 2), acting as a smoothing firmware. The rotation and translational movement of the cylindrical shank of the drill causes, under the action of contact friction forces, rapid (10-15 s) heating of the hole surface to $200-300{ }^{\circ} \mathrm{C}$ and the formation of a pseudo-liquid mass $[9,12]$. The pressure of the cylindrical insertion (of the shank) on the hole walls, as well as its rotational and translational movements ensure uniform distribution of the softened (pseudo-liquid) binder over the entire surface, press the protruding pile into the binder, prevent the tool from grasping and jamming in the hole being machined, provide high quality surface. For example, when processing holes with a diameter of 11 , 14.5 and $18 \mathrm{~mm}$, the surface roughness parameter decreases from $R z=40-20 \mu \mathrm{m}$ (4th class of surface roughness) to $R a=2.5-1.6 \mu \mathrm{m}$ (6th class) [9].

Specific difficulties of quality assurance occur when cutting holes in laminated hybrid composite materials consisting of alternating layers of various composite materials, for example, fiberglass-organo-

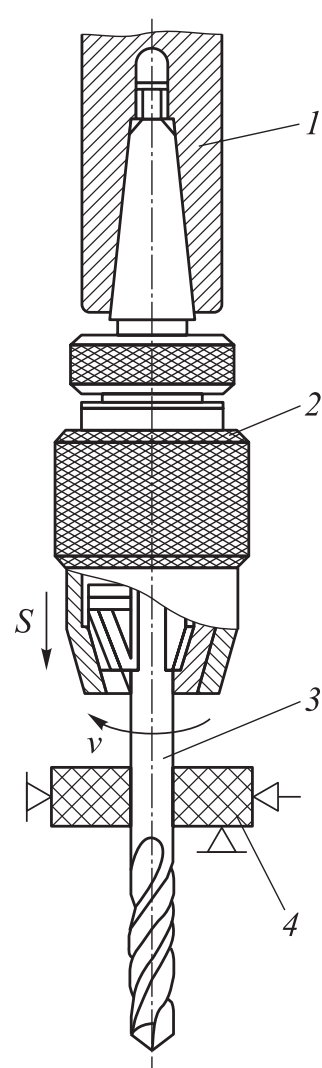

Fig. 2. Scheme of processing holes in organoplastic with thermomechanical action:

1 is machine spindle; 2 is drill chuck; 3 is drill; 4 is blank plastic, organoplastic-carbon-plastic, etc. In this case, the cutting tool alternately interacts with materials whose properties as a processing object vary significantly. This makes it extremely difficult to ensure rational processing conditions as a whole, but the main thing is associated with the low quality of the machined surfaces of the holes [13-16].

So, if when drilling the hole axis is perpendicular to the arrangement of layers of different composites, then annular protrusions and cavities are formed on the treated surface, caused by different elastic properties (elastic afterimpact) of materials that make up the design of polymer composite materials. For example, when processing laminated hybrid composite materials of fiberglass-organoplastic with drills with a diameter of $13 \mathrm{~mm}$, the annular layers of organoplastic experience a shrinkage of the hole diameter by 
0.1-0.12 $\mathrm{mm}$. In addition, a significant pile height is formed on their surfaces. Layers of fiberglass on the contrary undergo an increase in the diameter to $0.05 \mathrm{~mm}$.

If the requirements for lack of fleecy on the treated surface are not very rigid (for example, the surface is prepared for bonding with another product), then an impactive solution to the problem of processing holes in multilayer hybrid composite materials is to use a drill of a special design [4, 17]. The cutting part of the drill is made in the form of a plate (Fig. 3), which, along with the main cutting edges and jumper (as in a conventional spiral drill), has two auxiliary undercutting edges - cuts. Auxiliary undercutting edges are located on the opposite end of the plate from the main cutting edges and are directed toward the shank.

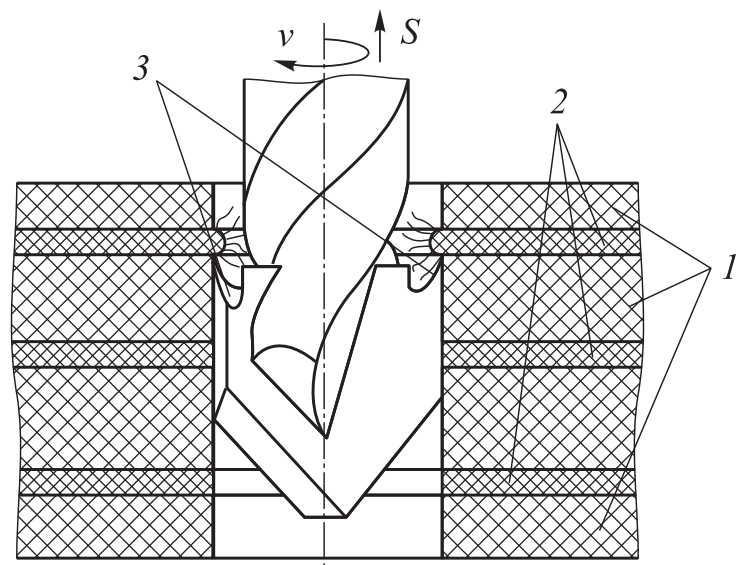

Fig. 3. Scheme of cutting a laminated hybrid composite material with a drill with auxiliary undercutting edges:

1 is fiberglass; 2 is organoplastic; 3 is undercut edges

At first, with normal inning, drilling is carried out with the main cutting edges with alternate cutting of the composite layers, for example, fiberglass, organoplastic, etc. The main cutting edges have a rational sharpening geometry as applied to the processing of fiberglass. Auxiliary undercutting edges are not involved in the work. In this case, the layers of organoplastic shrink and form a fuzzy surface. During the reverse inning (drill outlet), only auxiliary undercutting edges (Fig. 3) work, having a rational sharpening geometry applied to the treatment of organoplastic. Sharp cutting edges remove portions of organoplastic layers that are out of shape and protrude beyond the surface of the treated surface, without affecting the main layers of fiberglass. 
The use of such a drill, which can carry out the cutting process both in direct and reverse course, alternately creating optimal processing conditions for the material of each layer constituting the hybrid composite material, improves the productivity and quality of processing of multilayer composite materials, especially in cases where the physicomechanical properties of the reinforcing components differ significantly.

An independent technological task is to ensure the quality of the edges of the hole at the inlet and outlet of the cutting tool, where the delamination of the material being processed occurs and chipping appears $[2,7,18]$. When processing holes in fibrous composite materials with axial tools, in addition to delamination and chipping, a pile is formed due to cutting the fibers and displacing them towards the free surface (Fig. 4).

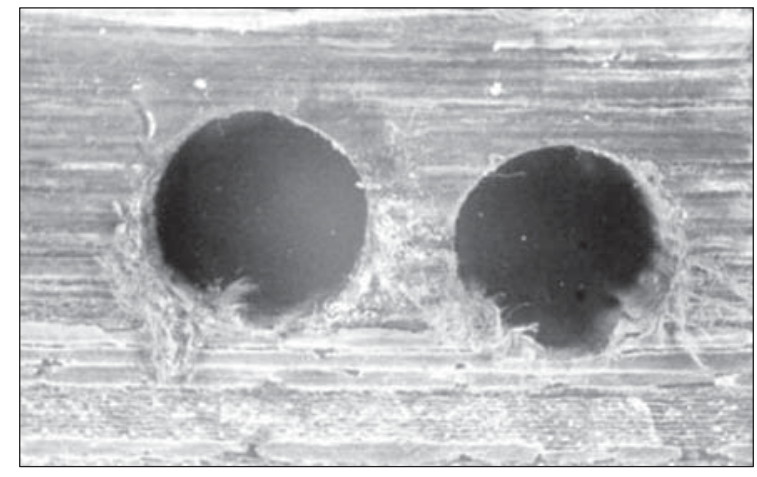

Fig. 4. View of holes at the tool inlet when drilling layered organoplastic CBM-6

To eliminate these defects allows the cutting method with additional technological coating. To this end, a thin layer (approximately $0.3-0.5 \mathrm{~mm}$ ) of the coating is applied on the surface areas at the drilling sites (Fig. 5). Technological coating displaces the position of the edges of the hole $d$ in the base material with respect to the free surfaces $c$, strengthens the edges of the formed hole during incision and the tool outlet, prevents their destruction and the appearance of pile during the drilling, countersinking and reaming of the holes.

Another way to achieve high quality of the edges of the holes is to create in the outer layers of the product compressive stresses that prevent delamination and chipping of the material during incision with the axial tool [19]. For these purposes, a conductor-type compression sleeve (Fig. 6) is used, the sharp edges of which with the required specific pressure $(0.4-0.8 \mathrm{~N} / \mathrm{mm})$ are penetrated into the material to be processed to a depth of $\sim 0.5 \mathrm{~mm}$. 


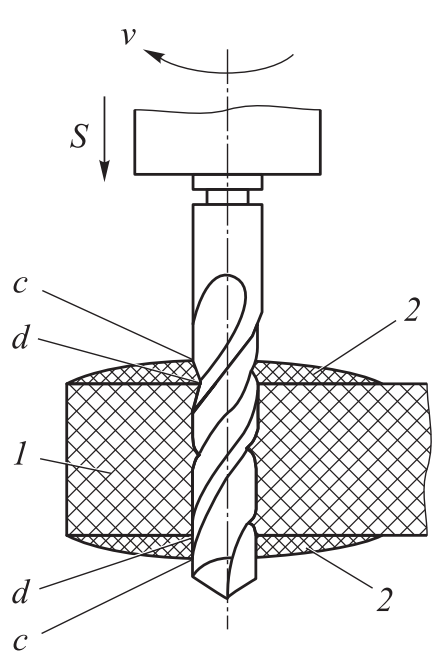

Fig. 5. Drilling holes with the use of additional technological coatings:

1 is processed composite material; 2 is additional technological coating

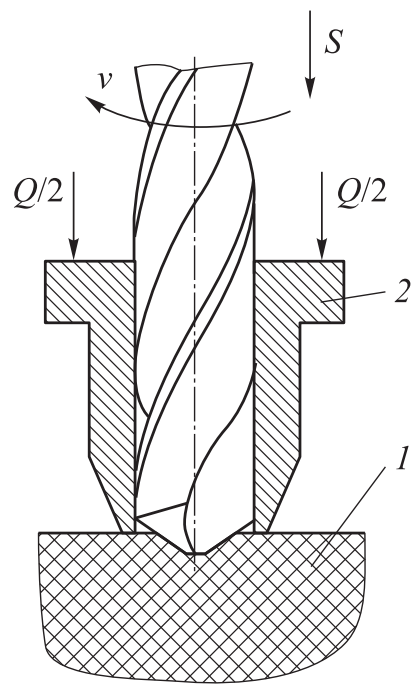

Fig. 6. The scheme of processing holes with the use of a clamping sleeve with sharp edges:

1 is blank; 2 is clamping sleeve; $Q$ is clamping force

Similarly, the required quality of the edges of the holes is achieved at the tool outlet, if compressive stresses are created on the inner surface of the shell structure or plate in the treatment area, preventing the composite from being destroyed by the impact of the cutting tool outside the cutting line. In Bauman Moscow State Technical University developed a number of devices that implement this provision in relation to the features of the designs of various products and various conditions of their processing [4].

Conclusion. Thus, the use of non-traditional technologies, which are based on developed in Bauman Moscow State Technical University methods for improving the quality of processing holes in products made of polymer composite materials - cutting with additional technological coating, with a targeted change in the stress-strain state of the material in the treatment area, with a thermomechanical impact on the material, the use of non-standard cutting tool designs and accessories, can significantly reduce (on 1-3 classes) the roughness of the treated surface and completely eliminate the pile when cutting fibrous polymer composite materials, prone to the formation of fluffiness, to ensure the quality of the edges of the hole at the inlet and outlet of the tool. The considered technological solutions also contribute to improving the quality of hole processing when drilling multilayer hybrid composite materials.

Translated by K. Zykova 


\section{REFERENCES}

[1] Zaloga V.A., ed. Mekhanicheskaya obrabotka kompozitsionnykh materialov pri sborke letatel'nykh apparatov [Mechanical processing of composites at aircraft assembly process]. Sumy, Universitetskaya kniga Publ., 2013.

[2] Mozgovoy N.I., Markov A.M. Research on process of quality index formation of the holes in fiberglass parts. Polzunovskiy vestnik, 2009, no. 1-2, pp. 284-287 (in Russ.).

[3] Stepanov A.A. Obrabotka rezaniem vysokoprochnykh kompozitsionnykh materialov [Cutting work of high-strength composites]. Leningrad, Mashinostroenie Publ., 1987.

[4] Yaroslavtsev V.M. Obrabotka rezaniem polimernykh kompozitsionnykh materialov [Cutting work of polymer composites]. Moscow, Bauman MSTU Publ., 2012.

[5] Makarov V.F., Meshkas A.E., Shirinkin V.V. Research of processes of machining of details of aerospace technics from new composite materials. Novye materialy $i$ tekhnologii $v$ mashinostroenii [Science Intensive Technologies in Mechanical Engineering], 2015, no. 22, pp. 14-22 (in Russ.).

[6] Frolov K.V., ed. Mashinostroenie. Entsiklopediya. T. III-3. Tekhnologiya izgotovleniya detaley mashin [Mechanical engineering encyclopedia. Vol. III-3. Machine part production technology]. Moscow, Mashinostroenie Publ., 2000.

[7] Verezub N.V., Tarasyuk A.P., Khavin G.L., et al. Mekhanicheskaya obrabotka voloknistykh polimernykh kompozitov [Mechanical processing of fiber polymer composites]. Khar'kov, Izd-vo KhNADU (KhADI) Publ., 2001.

[8] Yaroslavtsev V.M., Sabel'nikov V.V., Gusenko A.Yu. Technological possibilities of cutting finish processing of fiber composites using technological coating. Izvestiya vysshikh uchebnykh zavedeniy. Mashinostroenie [Proceedings of Higher Educational Institutions. Machine Building], 1998, no. 4-6, pp. 100-104 (in Russ.).

[9] Yaroslavtsev V.M. New technologies for surface layer quality improvement in cutting fibrous polymer composite materials. Vestn. Mosk. Gos. Tekh. Univ. im. N.E. Baumana, Mashinostr. [Herald of the Bauman Moscow State Tech. Univ., Mechan. Eng.], 2017, no. 6, pp. 79-88 (in Russ.). DOI: 10.18698/0236-3941-2017-6-79-88

[10] Yaroslavtsev V.M. New characteristic of metal machinability by cutting. Izvestiya vysshikh uchebnykh zavedeniy. Mashinostroenie [Proceedings of Higher Educational Institutions. Machine Building], 1989, no. 5, pp. 144-148 (in Russ.).

[11] Semenov B.I., Ignatova E.V. Joining methods for uniform and non-uniform materials and composites, which are promising for use in rocket production. Vestn. Mosk. Gos. Tekh. Univ. im. N.E. Baumana, Mashinostr. [Herald of the Bauman Moscow State Tech. Univ., Mechan. Eng.], 2005, spec. iss. "Composite materials and constructions in technology", pp. 99-105 (in Russ.).

[12] Yaroslavtsev V.M. Effect of deformational structural anisotropy of processed materials on cutting force. Izvestiya vysshikh uchebnykh zavedeniy. Mashinostroenie [Proceedings of Higher Educational Institutions. Machine Building], 1976, no. 12, pp. 156-159 (in Russ.).

[13] Ivanov Yu.N. Drilling the holes in the mixed packets. Izvestiya Samarskogo nauchnogo tsentra RAN [Izvestia RAS SamSC], 2014, vol. 16, no. 1-5, pp. 1402-1406 (in Russ.). 
V.M. Yaroslavtsev

[14] Vorob'yev Yu.A., Nikolenko A.I., Vorob'yev A.Yu. Analysis of study on drilling of mixed packets from composite and titanium alloys. Aviatsionno-kosmicheskaya tekhnika $i$ tekhnologiya, 2008, no. 2, pp. 32-38 (in Russ.).

[15] Yaroslavtsev V.M. Mechanics of cutting process of plastically deformed metals with non-uniform properties of cutted layer. Vestn. Mosk. Gos. Tekh. Univ. im. N.E. Baumana, Mashinostr. [Herald of the Bauman Moscow State Tech. Univ., Mechan. Eng.], 1993, no. 4, pp. 93-103 (in Russ.).

[16] Ramulu M., Branson T., Kim D. A study on the drilling of composite and titanium stacks. Composites Structures, 2001, vol. 54, no. 1, pp. 67-77.

DOI: $10.1016 / \mathrm{S} 0263-8223(01) 00071-\mathrm{X}$

[17] Chigrinets E.G., Sibirskiy V.V., Shevtsov S.N. Experimental investigation on the quality of holes in the multi-layered GFRP-titanium obtained in drilling operations. Inzhenernyy vestnik Dona [Engineering Journal of Don], 2015, vol. 37, no. 3, pp. 155-167 (in Russ.).

[18] Lobanov D.V., Sidorenko S.A. Modelling built-up constructions of turning tools for processing composite products. Trudy Bratskogo gosudarstvennogo universiteta. Ser. Estestvennye i inzhenernye nauki, 2016, vol. 2, pp. 17-22 (in Russ.).

[19] Baldaev L.Kh., ed. Gazotermicheskoe napylenie [Gas-thermal evaporation]. Moscow, Staraya Basmannaya Publ., 2015.

Yaroslavtsev V.M. - Dr. Sc. (Eng.), Professor, Department of Material Processing Technologies, Bauman Moscow State Technical University (2-ya Baumanskaya ul. 5, str. 1, Moscow, 105005 Russian Federation).

\section{Please cite this article as:}

Yaroslavtsev V.M. Ensuring the quality of treatment of holes in products from polymeric composite materials. Herald of the Bauman Moscow State Technical University, Series Mechanical Engineering, 2019, no. 3, pp. 78-88.

DOI: 10.18698/0236-3941-2019-3-78-88 